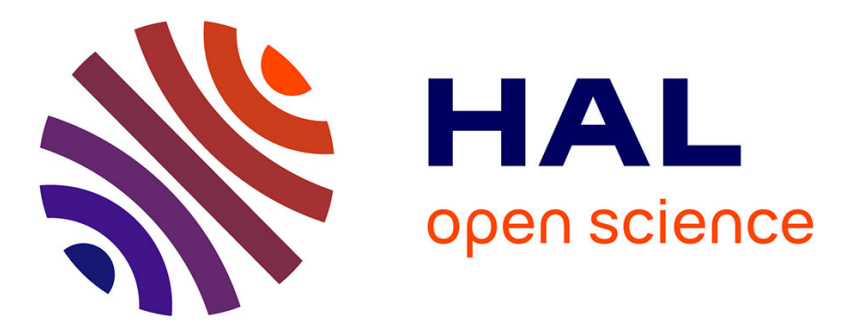

\title{
What makes a difference? Understanding the role of protective factors in Hungarian adolescents' depressive symptomatology
}

\author{
Bettina Franciska Piko, Eszter Kovacs, Kevin M. Fitzpatrick
}

\section{- To cite this version:}

Bettina Franciska Piko, Eszter Kovacs, Kevin M. Fitzpatrick. What makes a difference? Understanding the role of protective factors in Hungarian adolescents' depressive symptomatology. European Child and Adolescent Psychiatry, 2009, 18 (10), pp.617-624. 10.1007/s00787-009-0022-y . hal-00535147

\section{HAL Id: hal-00535147 \\ https://hal.science/hal-00535147}

Submitted on 11 Nov 2010

HAL is a multi-disciplinary open access archive for the deposit and dissemination of scientific research documents, whether they are published or not. The documents may come from teaching and research institutions in France or abroad, or from public or private research centers.
L'archive ouverte pluridisciplinaire HAL, est destinée au dépôt et à la diffusion de documents scientifiques de niveau recherche, publiés ou non, émanant des établissements d'enseignement et de recherche français ou étrangers, des laboratoires publics ou privés. 


\title{
What makes a difference? Understanding the role of protective factors in Hungarian adolescents' depressive symptomatology
}

\author{
Bettina Franciska Piko · Eszter Kovacs • \\ Kevin M. Fitzpatrick
}

Received: 20 January 2009/Accepted: 1 April 2009/Published online: 21 April 2009

(C) Springer-Verlag 2009

\begin{abstract}
Depressive symptomatology contributes to morbidity and mortality across the life course. Among factors predicting adolescent depressive symptomatology, it has become increasingly important to identify factors that prevent or minimize it, i.e., protective factors. This study examines protective factors operating in three contextual domains (parental, school-related and individual) that hold promise for explicating their role in the prevention of depressive symptomatology among a non-clinical adolescent population in Hungary. Data from this cross-sectional survey were gathered using self-administered questionnaires from adolescents $(N=881$; aged between 14 and 20 years; $44.6 \%$ females) from five randomly selected high schools in Szeged, Hungary. Multiple regression analyses revealed that individual level variables (i.e., life satisfaction and optimism) were important predictors of adolescent depressive symptomatology. Among parental variables, social support from the same-sex parents lowered depressive symptoms. In addition, having dinner together with one's family was a significant protective factor for boys, whereas talking about problems with parents was significant for girls. In our study, school-related factors played only a limited role in reducing depressive symptoms; being happy with school was a protective factor only for boys. As a consequence, our findings draw attention to important gender differences in the structuring of protective factors and their role in reducing depressive symptoms, which will
\end{abstract}

B. F. Piko $(\bowtie) \cdot$ E. Kovacs

Department of Behavioral Sciences, University of Szeged,

Szentharomsag street 5, 6722 Szeged, Hungary

e-mail: pikobettina@yahoo.com

K. M. Fitzpatrick

Department of Sociology and Criminal Justice,

University of Arkansas, Fayetteville, AR, USA likely continue to be an important part of the prevention conversation.

Keywords Adolescent depression - Gender differences . Protective factors

\section{Introduction}

Depressive symptomatology contributes to morbidity and mortality across the life course generally and in adolescence specifically [7]. Recently, researchers and clinicians have begun to increasingly focus on detecting possible protective factors in understanding the depression sequelae, after addressing the source of vulnerability, and their role in minimizing negative health outcomes for youth [30]. Protection consists of attributes with direct ameliorative effects that function in a variety of contextual domains, including individual, family and school [14]. Even when risk factors are found to be resistant to change, protective factors, when applied appropriately, act to neutralize or decrease the negative effects of risk. With this potential to directly impact health outcomes, it seems that special attention should be paid to better understand the role of protective factors and their implications for practice [10]. Thus, as a growing body of literature encourages [10, 14, 30], the central aim of this paper is to examine the role of protective factors in three domains, parental, school-related, and individual and their relationships with depressive symptomatology among Hungarian adolescents.

Parental protective factors are one of the main foci of our research. Despite the fact that peers become an increasingly important source of support as youth restructure their social networks through adolescence, parental intimacy and communications with parents remain 
important elements of protection against negative health risks [9, 19]. From a developmental psychopathology perspective, vulnerability stems from the controversy that establishing autonomy goes together with the task of maintaining positive relationships with parents and developing close peer relationships [2]. In relation to psychosocial adjustment, the quality of attachment to parents has been found to be a key protective factor [22]. In a recent study of adolescents, secure attachment to parents was found to be related to fewer depressive symptoms [13]. Both paternal and maternal attachment appears important, and attachment to the same-sex parent was related to peer support and was an important correlate for youth's psychological well-being and adjustment. Less secure attachment, on the other hand, was related to more suicidal ideation among a clinically depressed group of adolescents [3]. Certainly, some have argued that secure attachment may act as a buffer, for example, high economic risk was associated with depressive symptoms only among insecurely attached youth [8]. Apart from secure attachment, however, a high level of parental psychological controleven when the control may be too harsh-could disturb a youth's autonomy efforts and be linked to more psychosomatic [18] or depressive symptoms [15]. A less directive aspect of parental control (e.g., having dinner together with parents or talking with parents about problems) may serve as a protection against both externalizing and internalizing problem behaviors and mental health problems [4]. In addition, studies suggest that gender differences in the role of family level protection against adolescents' depression requires further examination, revealing that cohesive family relationships and parental attachment served as protective factors for girls more than for boys [15, 21]. Other studies have found that family cohesion protects youth against the effects of stress, in this case, more for boys than girls [31].

Besides parental protective factors, school-related and individual protections are also considered to be important to understanding the risk-mental health symptom relationship. School has a significant effect on adolescent psychosocial development, for example, school climate and attachment to a school and its teachers also can serve as a source of protection for youth, particularly since youth spend a great deal of time in school [26, 27]. Among individual protective factors, optimism, that is, a tendency to have positive expectations about life and their social surroundings has been found to be a key factor in developing and maintaining resilience; acting as an important protective mechanism against depressive symptomatology [28]. Life satisfaction may also act as a protective mechanism against depressive symptomatology since not only does depression lower life satisfaction, but greater levels of life satisfaction also contribute to an increase in psychological well-being and general mental health $[1,11]$.

Based on a substantial literature and the above proposed assumptions, the central goal of the present paper is to examine a set of protective factors in three domains (parental, school-related and individual) that hold some promise with explicating their role in the prevention of depressive symptomatology among a non-clinical adolescent population in Hungary. Because of the developmental challenge of the harmonizing positive relationship with parents and developing autonomy from them, our primary interest is to look at how social support, particularly parental attachment, influences depressive symptomatology. Since there are well-documented gender differences in the functioning of social networks during adolescence [18], we believe that gender may be an important socio-demographic factor related to the frequency of depressive symptoms. Thus, we analyze different multivariate models (including each domain of protection) for predicting depressive symptomatology in boys and girls separately.

\section{Methods}

Participants and procedure

Data were collected in spring 2008. The final sample consists of 881 high school students (14-20 years of age) from five high schools in Szeged, a major metropolitan center in the southeastern region of Hungary. In the Hungarian education system, high schools have five grades/levels and the fifth level is generally for those youth choosing not to continue their studies in higher education. The five schools were chosen randomly from a list of all high schools in Szeged; the high school classes were chosen randomly from a sample of all classes in the population of high schools. Of the sampled students, $44.6 \%$ were female and the median age of the sample was 16 years of age (mean $=16.6$ years; $\mathrm{SD}=1.3$ years). Of the 900 questionnaires sent out (approximately 13\% of the entire high school population in Szeged), 881 were returned. This final sample count gave us a response rate of approximately $97.9 \%$. The remaining students likely consisted of youth absent or those youth whose parents did not want them participating in the study. Parents were informed about the study and their consent was obtained prior to the data collection. A standardized procedure of administration was followed. Trained graduate students distributed the questionnaires to students in each class, after briefly explaining the study objectives and giving the necessary instructions, students completed the questionnaires during the class period. Student participation was 
voluntary and confidentiality was emphasized, noting that the data were being collected for research purposes only.

\section{Measures}

Depressive symptomatology was measured by a shortened version of the original 27-item Children's Depression Inventory (CDI) that is a self-rated depressive symptom scale for young children adapted from the Beck Depression Inventory for adults [12]. Each item of the original and shortened versions assesses a single symptom, such as sadness, and was coded from 0 to 2 . The shortened version of the CDI, based on the current data, was reliable with a Cronbach's alpha of 0.74. We weighted the shortened CDI by a factor of 3.375 (number of original CDI items 27/ shortened version items $8=3.375$ ) for purposes of comparing this sample with other Hungarian, European and US samples of adolescents. Thus, the mean score and SD for this sample was $8.1(\mathrm{SD}=8.0)$, whereas a previous sample of high school students from Szeged in 2000 yielded a mean CDI score of 10.2 ( $\mathrm{SD}=8.2)$ [19]. The cutoff CDI score for the upper $10 \%$ of the distribution for the current sample was 20 .

\section{Protective factors}

The following protective factors were assessed from multiple domains: social support from parents, talking about problems with parents, having dinner together with the family (parental protective factors), how much the children were happy with school, high academic achievement and talking about problems with teachers (school-based protective factors), optimism and life satisfaction (individual protective factors) $[6,20,24]$.

Among the parental protective factors, the measures of Perceived Social Support developed by Turner and Marino [29] were used to assess the level of satisfaction with the support experienced by youth as given from their mother and/or father. Each of the subscales contained six items and was scored so that higher scores indicated greater satisfaction with the perceived support. Satisfaction was measured by the amount of agreement youth had with each of the items, e.g., "I feel very close to my father/mother" or "I often feel really appreciated by my father/mother". Responses were based on the following categories: $4=$ very much like my experience, $3=$ much like my experience, $2=$ somewhat like my experience and $1=$ not at all like my experience. This measurement scheme has been found to work well in assessing the quality of parentadolescent relationship in Hungarian adolescent samples [16]. The final perceived social support scales were coded from 6-24 and reliable with Cronbach's alpha coefficients of 0.92 (father support) and 0.91 (mother support). In addition, we asked students, how often they talked to their parents about their personal problems. This measure was an ordinal level variable where $1=$ never talk with my parents, $2=$ hardly ever, $3=$ sometimes, $4=$ most of the time, and $5=$ always. We also asked them how often they eat dinner together with their family. The response categories were the following: $1=$ never, $2=$ few times, $3=$ some of the time, $4=$ most of the time, and $5=$ all of the time $[6,20]$.

As to school climate and protective mechanisms operating in the school domain, we asked students how happy they were with school and those responses ranged from $1=$ very unhappy to $4=$ very happy $[6,20]$. The high academic achievement variable was a self-report measure indicating "grades students mostly get in school" ranging from $1=$ mostly D's and F's to $7=$ mostly A's. In addition, an ordinal variable was constructed to assess how often students talked with teachers about their personal problems with responses including: $1=$ never, $2=$ hardly ever, $3=$ sometimes, $4=$ most of the time, and $5=$ all of the time $[6,20]$.

Finally, in considering the individual domain of protection, life satisfaction was measured using a Satisfaction With Life Scale [5]. This measurement is a widely used scale among Hungarian adolescent populations [17]. The scale consisted of five statements including (1) "In most ways my life is close to my ideal"; (2) "The conditions of my life are excellent"; (3) "I am satisfied with my life"; (4) "So far I have gotten the important things I want in life"; and (5) "If I could live my life over, I would change almost nothing". Students indicated how strongly they agreed with each item and those responses ranged from $1=$ strongly disagree to $7=$ strongly agree. The final scale had a range of 5-35 and was reliable with a Cronbach's alpha of 0.83 . A second individual level protective measure was optimism which was measured using the Hungarian version of the Life Orientation Test (LOT) [23]. The LOT consists of eight items (plus four filler items that were not scored as part of the scale) assessing generalized expectancies for positive versus negative outcomes. Students were asked to indicate their degree of agreement with statements such as "In uncertain times, I usually expect the best" or "I hardly ever expect things to go my way" (reverse item). A fivepoint response scale was used ranging from $0=$ strongly disagree to $4=$ strongly agree (except for four reversecoded items). This scale was reliable with a Cronbach's alpha of 0.70 .

Statistical methods

SPSS for MS Windows Release 13.0 was used in the calculations, with maximum significance level set to 0.05 . Gender differences were calculated using $t$ tests and 
Chi-square tests. The role of parental, school-related and individual variables influencing depressive symptomatology was assessed using multiple regression analysis. Model 1 examined parental variables, Model 2 school-related variables, and Model 3 added individual level variables. Due to expected gender differences in the structure of protective factors as discussed earlier, regression analyses were conducted separately for boys and girls.

\section{Results}

Table 1 provides detailed descriptive statistics for the samples by gender. The mean CDI score was 7.05 $(\mathrm{SD}=8.03)$ for boys and 9.28 $(\mathrm{SD}=7.90)$ for girls. Gender differences in depressive symptoms were significant $(P<0.001)$ as expected. High academic achievement scores $(P<0.001)$, perceived social support from mother $(P<0.05)$, talking about problems with parents and teachers $(P<0.001)$, and being happy with school $(P<0.05)$ were all correlated higher among female students compared to male students. However, there were no significant gender differences in terms of optimism, life satisfaction and levels of perceived social support from father or the frequencies of having dinner together with one's family $(P>0.05)$.

Table 2 presents zero-order correlations among the variables. Depressive symptom scores were negatively related to perceived social support from both father and mother, life satisfaction and optimism, other parental variables (talking about problems with parents, having dinner together with the family), school-related variables (high academic achievement, being happy with school and talking about problems with teachers), that is, with all of
Table 1 Gender differences in depression scores and protective factors in the sample of Hungarian adolescents $(N=881)$

$* t$ test, $* *$ Chi-square test

\begin{tabular}{|c|c|c|c|}
\hline & Boys $(n=488)$ & Girls $(n=393)$ & Significance $(P)$ \\
\hline $\begin{array}{l}\text { Depressive symptomatology }(\mathrm{CDI})^{*} \\
\text { mean }(\mathrm{SD})\end{array}$ & $7.05(8.03)$ & $9.28(7.90)$ & $<0.001$ \\
\hline Social support from father* mean (SD) & $16.98(4.87)$ & $16.32(5.78)$ & $>0.05$ \\
\hline Social support from mother* mean (SD) & $19.56(3.92)$ & $20.15(4.58)$ & $<0.05$ \\
\hline $\begin{array}{l}\text { Optimism (Life Orientation Test)* } \\
\text { mean (SD) }\end{array}$ & $28.05(5.33)$ & $28.18(5.72)$ & $>0.05$ \\
\hline $\begin{array}{l}\text { Life satisfaction (Satisfaction with Life } \\
\text { Scale)* }\end{array}$ & $22.03(6.13)$ & $21.49(6.65)$ & $>0.05$ \\
\hline $\begin{array}{l}\text { High academic achievement (marks) } \\
(\text { Scale } 1-7)^{*} \text { mean }(\mathrm{SD})\end{array}$ & $3.38(1.45)$ & $3.80(1.46)$ & $<0.001$ \\
\hline \multicolumn{4}{|l|}{ Dinner together with the family $(\%)^{* *}$} \\
\hline Never & 8.7 & 8.7 & \multirow[t]{5}{*}{$>0.05$} \\
\hline Once or twice & 16.1 & 25.4 & \\
\hline Several times & 31.7 & 27.8 & \\
\hline A lot of times & 30.2 & 26.0 & \\
\hline All the time & 13.3 & 12.1 & \\
\hline \multicolumn{4}{|l|}{ Talking about problems with parents $(\%)^{* * *}$} \\
\hline Never & 7.2 & 5.9 & \multirow[t]{5}{*}{$<0.001$} \\
\hline Hardly ever & 23.4 & 14.5 & \\
\hline Sometimes & 33.9 & 25.4 & \\
\hline Most of the time & 25.5 & 32.1 & \\
\hline All of the time & 10.1 & 22.1 & \\
\hline \multicolumn{4}{|l|}{ How happy are you with school right now?** } \\
\hline Very unhappy & 7.0 & 4.3 & \multirow[t]{4}{*}{$<0.01$} \\
\hline Unhappy & 19.9 & 12.0 & \\
\hline Happy & 62.5 & 69.7 & \\
\hline Very happy & 10.6 & 14.0 & \\
\hline \multicolumn{4}{|l|}{ Talking about problems with teachers $(\%)^{* *}$} \\
\hline Never & 48.9 & 37.6 & \multirow[t]{5}{*}{$<0.001$} \\
\hline Hardly ever & 26.3 & 39.4 & \\
\hline Sometimes & 17.0 & 18.2 & \\
\hline Most of the time & 5.7 & 3.1 & \\
\hline All of the time & 2.1 & 1.8 & \\
\hline
\end{tabular}


Table 2 Zero-order correlation matrix $(n=881)$

\begin{tabular}{|c|c|c|c|c|c|c|c|c|c|c|c|}
\hline Variables & 2 & 3 & 4 & 5 & 6 & 7 & 8 & 9 & 10 & 11 & 12 \\
\hline 1. Gender & 0.01 & $0.14 * * *$ & -0.06 & $0.07 *$ & 0.01 & -0.04 & $0.13 * * *$ & $-0.07^{*}$ & $0.19 * * *$ & $0.12 * * *$ & 0.03 \\
\hline 2. Age & - & 0.05 & $-0.07 *$ & -0.05 & -0.06 & $-0.07 *$ & -0.04 & $-0.10 * *$ & -0.05 & $-0.08^{*}$ & 0.06 \\
\hline $\begin{array}{l}\text { 3. Depressive } \\
\text { symptomatology } \\
\text { (CDI) }\end{array}$ & - & - & $-0.33 * * *$ & $-0.33^{* * *}$ & $-0.46^{* * *}$ & $-0.48 * * *$ & $-0.10 * *$ & $-0.24 * * *$ & $-0.28 * * *$ & $-0.24 * * *$ & $-0.08^{*}$ \\
\hline $\begin{array}{l}\text { 4. Social support from } \\
\text { father }\end{array}$ & - & - & - & $0.24 * * *$ & $0.19 * * *$ & $0.33 * * *$ & $0.16 * * *$ & $0.26 * * *$ & $0.31 * * *$ & $0.18 * * *$ & $0.14 * * *$ \\
\hline $\begin{array}{l}\text { 5. Social support from } \\
\text { mother }\end{array}$ & - & - & - & - & $0.23 * * *$ & $0.32 * * *$ & $0.14 * * *$ & $0.22 * * *$ & $0.49 * * *$ & $0.17 * * *$ & $0.11 * *$ \\
\hline 6. Optimism (LOT) & - & - & - & - & - & $0.43 * * *$ & $0.12 * *$ & $0.14 * *$ & $0.27 * * *$ & $0.21 * * *$ & $0.10 * *$ \\
\hline $\begin{array}{l}\text { 7. Life satisfaction } \\
\text { (SWL) }\end{array}$ & - & - & - & - & - & - & $0.18 * * *$ & $0.31 * * *$ & $0.41 * * *$ & $0.28 * * *$ & $0.19 * * *$ \\
\hline $\begin{array}{l}\text { 8. High academic } \\
\text { achievement (marks) }\end{array}$ & - & - & - & - & - & - & - & $0.09 * *$ & $0.16 * * *$ & $0.17 * * *$ & $0.18 * * *$ \\
\hline $\begin{array}{l}\text { 9. Dinner with the } \\
\text { family }\end{array}$ & - & - & - & - & - & - & - & - & $0.35 * * *$ & $0.12 * * *$ & $0.16^{* * *}$ \\
\hline $\begin{array}{l}\text { 10. Talking about } \\
\text { problems with } \\
\text { parents }\end{array}$ & - & - & - & - & - & - & - & - & - & $0.22 * * *$ & $0.39 * * *$ \\
\hline 11. Happy with school & - & - & - & - & - & - & - & - & - & - & $0.13 * * *$ \\
\hline $\begin{array}{l}\text { 12. Talking about } \\
\text { problems with } \\
\text { teachers }\end{array}$ & - & - & - & - & - & - & - & - & - & - & - \\
\hline
\end{tabular}

$* P<0.05, * * P<0.01, * * * P<0.001$; two-tailed test

the proposed protective factors. There was a positive correlation between optimism and perceived social support from parents, and between life satisfaction and perceived parental social support. High academic achievement was positively correlated with optimism and life satisfaction and also with perceived social support from parents. For the most part, there were positive intercorrelations between different domains of protective factors suggesting that there might be an important cumulative protective affect developing among this group of adolescents. The relationship with gender again suggests that there may be important differences in the role of some parental variables in predicting depressive symptomatology between boys and girls.

Tables 3 and 4 present regression estimates for depressive symptomatology scores, where multiple regression models were used to examine the relative effects of protective factors in different domains (parental variables in Model 1, school-related variables in Model 2, and individual level variables in Model 3). Table 3 shows the results for boys and among parental variables, perceived social support from father and having dinner together with the family remained significant even in the final model. Among school-related variables, being happy with school was a significant correlate with depressive symptomatology. Finally, both optimism and life satisfaction were significant correlates with depressive symptomatology for boys. Table 4 shows the regression results for girls and among parental variables, both father and mother perceived social support were significant, however, only the latter remained significant in the final model. In addition, talking about problems with parents was also a significant correlate with symptoms. Among school-related variables, talking about problems with teachers was significant; however, in the inverse (positive) direction. Finally, like the case for boys, both optimism and life satisfaction were significant correlates with depressive symptoms. The blocks of these variables explained $31 \%$ of the total variation in depressive symptomatology scores for boys and $47 \%$ of the total variation in depressive symptomatology for girls.

\section{Discussion}

Research continues to explore what factors serve as protection for youth against negative health outcomes, including mental health outcomes like depressive symptomatology [14, 19, 30]. Preventing adolescent depression is and will continue to be an important public health priority, since it has such a profound influence on later adult morbidity, quality of life, and mortality [7]. Mapping protective factors at different levels can help better 
Table 3 Regression models for depressive symptomatology among boys $(n=488)$
* $P<0.05, * * P<0.01$,

*** $P<0.001$; one-tailed $t$ test

a Standardized regression coefficients

${ }^{\mathrm{b}} R^{2}$ change is based on hierarchical $F$ test of significance

Table 4 Regression models for depressive symptomatology among girls $(n=393)$
$* P<0.05, * * P<0.01$,

*** $P<0.001$; one-tailed $t$ test

${ }^{a}$ Standardized regression coefficients

b $R^{2}$ change is based on hierarchical $F$ test of significance

\begin{tabular}{lllc}
\hline Protective factors & Model 1 & Model 2 & Model 3 \\
\hline Parental protection & & & \\
Social support from father & $-0.25^{* * * a}$ & $-0.23^{* * *}$ & $-0.15^{* *}$ \\
Social support from mother & -0.04 & -0.04 & 0.01 \\
Dinner with the family & $-0.13^{*}$ & $-0.13^{*}$ & $-0.09^{*}$ \\
Talking about problems with parents & -0.09 & -0.01 & 0.09 \\
School-related protection & & & -0.01 \\
High academic achievement & & -0.03 & -0.08 \\
Talking about problems with teachers & & -0.08 & $-0.17^{* * *}$ \\
Happy with school & & $-0.23^{* * *}$ & \\
Individual protection & & & $-0.25^{* * *}$ \\
Optimism & & & $-0.22^{* * *}$ \\
Life satisfaction & $20.049^{* * *}$ & $14.278^{* * *}$ & $26.939^{* * *}$ \\
Constant & $0.15^{* * * \mathrm{~b}}$ & $0.20^{* * *}$ & $0.31^{* * *}$ \\
$R^{2}$ & & & \\
\hline
\end{tabular}

\begin{tabular}{lccc}
\hline Protective factors & Model 1 & Model 2 & Model 3 \\
\hline Parental protection & & & \\
Social support from father & $-0.17^{* * \mathrm{a}}$ & $-0.15^{* *}$ & -0.06 \\
Social support from mother & $-0.28^{* * *}$ & $-0.26^{* * *}$ & $-0.16^{* *}$ \\
Dinner with the family & 0.01 & 0.01 & 0.01 \\
Talking about problems with parents & $-0.18^{* *}$ & $-0.22^{* * *}$ & $-0.12^{*}$ \\
School-related protection & & & \\
High academic achievement & & -0.01 & -0.05 \\
Talking about problems with teachers & & $0.13^{*}$ & $0.10^{*}$ \\
Happy with school & & $-0.10^{*}$ & -0.02 \\
Individual protection & & & $-0.39^{* * *}$ \\
Optimism & & & $-0.25^{* * *}$ \\
Satisfaction with life & $26.590^{* * *}$ & $22.009^{* * *}$ & $40.588^{* * *}$ \\
Constant & $0.22^{* * * \mathrm{~b}}$ & $0.24^{*}$ & $0.47^{* * *}$ \\
$R^{2}$ & & &
\end{tabular}

understand the psychosocial background and its complicated role in the development of mental health problems among adolescents like depression. Thus, the main goal of our study has been to examine a set of protective factors operating in multiple domains (parental, school-related and individual) and examine what influence they have in determining adolescents' depressive symptomatology.

A number of studies confirm that parents continue to play an important role in their children's lives even during adolescence; however, this developmental change clearly brings about changes in the parent-adolescent relationship [9, 15, 18, 19]. While parental monitoring was found to have an important protective effect on adolescent substance use [4, 20], a secure attachment to parents, the quality of time spent together, and parentchild communication seemed to be more important in lowering adolescent depressive symptoms [3, 22]. Studies also reported considerable gender differences not only in the amount of depressive symptomatology, but also in the risk and protective structure [15, 21, 31]. Our results support these findings, namely, having dinner together with one's family seems to be an important protective factor for boys, that is, spending time and eating together with family members makes a difference. On the other hand, talking about problems with parents was an important protective factor for girls. Perceived social support from parents was also significant predictor; however, father's perceived support remained significant in the multivariate analysis for boys, whereas mother's perceived support was significant for girls. The role of perceived social support from father is a particularly important protection against substance use during adolescence [16]. Our findings suggests that in the lowering of depressive symptoms, the same-sex parent plays the 
decisive role [13] perhaps as some part of a more complicated gender socialization puzzle.

School-related variables were another important set of protective factors. For example, being happy with school, accepting the social norms of school, and finding a good teacher-adolescent relationship appear to serve as a protection not only against substance use but also depressive symptomatology [4, 6, 19, 26, 27]. In our study, schoolrelated factors played only a limited role in influencing adolescents' depressive symptomatology, namely, being happy with school was a significant predictor only for boys. Among girls, talking about problems with teachers was a positive predictor, that it, not as a protective factor. Since our study is based on a cross-sectional design, this may suggest that talking with teachers about problems may be a consequence of girls' problem behavior and may not be serving at all as a source of protection.

Finally, individual level variables were found to be important predictors for adolescent depressive symptomatology. Life satisfaction and optimism both served as important sources of protection in lowering depressive symptoms during adolescence $[1,11,28]$. This reflects a positive psychology approach to mental health promotion that applies different techniques to enhance a more positive way of thinking and developing effective coping skills [25]. We should note here that parental, individual, and school-related factors are also interrelated in some very important ways in the bivariate analyses, which may be partially supporting the notion that protection is about the accumulation of such a benefit.

While these findings provide clear evidence to the role of protection, there are some important limitations to the present study that should be noted. Because of the cross-sectional study design, our results cannot provide a cause-and-effect relationship. Furthermore, we use selfreported data on depression without clinical diagnosis that does not enable us to determine adolescents' mental health status, e.g., levels of clinical depression. Due to the specific cultural context of the study (our sample consisted of Hungarian adolescents), the findings may not be generalizable since differences across cultures in lifestyle practices may result in different patterns of interrelationships. Despite any cultural differences, however, the role of these protective factors seems to be universal $[4,6,19,20]$ even if there may be differences in their relative significance.

Despite these limitations, we believe the data make a valuable contribution to our understanding of the nature of protection in various domains in adolescent depressive symptomatology. It seems that high school students in this sample may not really be able to benefit from schoolrelated protection, which needs to be further examined. On the other hand, parental protection is an important asset and resource in adolescents developing resilience. This finding supports previous studies on the continuous role of parental attachment in adolescent development [1, 3, 22]. Likewise, individual level protective factors also serve as a protection for both adolescent boys and girls. These findings have some important implications for community mental health promotion. Helping to develop good communication skills in homes and school may be an important preventive activity. Strengthening life satisfaction and optimism as bases of positive psychology interventions should also be part of programs designed to promote mental health. We also believe that our findings draw attention to the gender differences in the structuring of protective factors and their role in reducing depressive symptoms. For example, communication issues, such as talking about problems with parents seem to be important developmental asset for adolescent girls but not for boys. Instead, having dinner together as a family (which helps develop normative behaviors for adolescents) seems to be more relevant for boys. Gender differences in the structure of protection must continue to be an important part of the prevention conversation. Since adolescents' depression shows an increasing tendency around the world [7], we need to have a better understanding of what psychosocial influences contribute to this development. Future studies should continue to search for protective factors at different levels.

\section{References}

1. Adelman HS, Taylor L, Nelson P (1989) Minors' dissatisfaction with their life circumstances. Child Psychiatr Hum Dev 20:135147

2. Allen JP, Insabella G, Porter MR, Smith FD, Land D, Phillips N (2006) A social-interactional model of the development of depressive symptoms in adolescence. J Consult Clin Psychol 74(1):55-65

3. Armsden GC, McCauley E, Greenberg MT, Burke PM, Mitchell JR (1990) Parent and peer attachment in early adolescent depression. J Abnorm Child Psychol 18(6):683-697

4. Deković M (1999) Risk and protective factors in the development of problem behavior during adolescence. J Youth Adolesc 28:667-685

5. Diener E, Emmons RA, Larsen RJ, Griffin S (1985) The Satisfaction with Life Scale. J Pers Assess 49:71-75

6. Fitzpatrick KM (1997) Fighting among America's youth: a risk and protective factors approach. J Health Soc Behav 38:131-148

7. Friedman RA (2006) Uncovering an epidemic_-screening for mental illness in teens. N Engl J Med 355(26):2717-2719

8. Graham CA, Easterbrooks MA (2000) School-aged children's vulnerability to depressive symptomatology: the role of attachment security, maternal depressive symptomatology, and economic risk. Dev Psychopathol 12(2):201-213

9. Hair EC, Moore KA, Garrett SB, Ling T, Cleveland K (2008) The continued importance of quality parent-adolescent relationships during late adolescence. J Res Adolesc 18(1):187-200

10. Jessor R, Van Den Bos J, Vanderryn J, Costa FM, Turbin MS (1995) Protective factors in adolescent problem behavior: moderator effects and development change. Dev Psychol 31:923-933 
11. Koivumaa-Honkanen H, Kaprio J, Honkanen R, Viinamäki H, Koskenvuo M (2004) Life satisfaction and depression in a 15-year follow-up of healthy adults. Soc Psychiatr Psychiat Epidemiol 39:994-999

12. Kovacs M (1992) Children's Depression Inventory (CDI). MultiHealth Systems, Toronto

13. Liu Y-L (2006) Paternal-maternal attachment, peer support, social expectations of peer interaction, and depressive symptoms. Adolescence 41:705-721

14. Luthar SS, Cichetti D, Becker B (2000) The construct of resilience: a critical evaluation and guidelines for future work. Child Dev 71(3):543-562

15. Manongdo JA, Garcia R (2007) Mothers' parenting dimensions and adolescent externalizing and internalizing behaviors in a lowincome, urban Mexican American sample. J Clin Child Adolesc Psychol 36(4):593-604

16. Piko B (2000) Perceived social support from parents and peers: which is the stronger predictor of adolescent substance use? Subst Use Misuse 35(4):617-630

17. Piko B (2006) Satisfaction with life, psychosocial health, and materialism among Hungarian youth. J Health Psychol 11(6):827-831

18. Piko B (1998) Social support and health in adolescence: a factor analytical study. Br J Health Psychol 3:333-344

19. Piko BF, Fitzpatrick KM (2003) Depressive symptomatology among Hungarian youth: a risk and protective factors approach. Am J Orthopsychiatr 73(1):44-54

20. Piko BF, Fitzpatrick KM (2002) Without protection: substance use among Hungarian adolescents in high-risk settings. J Adolesc Health 30:463-466

21. Rubin C, Rubenstein JL, Stechler G, Heeren T, Halton A, Housman D, Kasten L (1992) Depressive affect in "normal" adolescents: relationships to life stress, family, and friends. Am J Orthopsychiatr 62:430-441

22. Scharf M, Mayseless O, Kivenson-Baron I (2004) Adolescents' attachment representations and developmental tasks in emerging adulthood. Dev Psychopathol 40(3):430-444

23. Scheier MF, Carver CS (1985) Optimism, coping and health: assessment and implications of generalized outcome experiences. Health Psychol 5:219-247

24. Search Institute (1998) Search Institute profiles of student life administration manual. Search Institute, Minneapolis

25. Seligman MEP (2002) Authentic happiness: using the new positive psychology to realize your potential for lasting fulfillment. Free Press, New York

26. Simons-Morton BG, Davis Crump A, Haynie DL, Saylor KE (1999) Student-school bonding and adolescent problem behavior. Health Educ Res 14:99-107

27. Somersalo H, Solantaus T, Almqvist F (2002) Classroom climate and the mental health of primary school children. Nord J Psychiatr 56:285-290

28. Steinhardt M, Dolbier C (2008) Evaluation of resilience intervention to enhance coping strategies and protective factors and decrease symptomatology. J Am Coll Health 56(4):445-453

29. Turner RJ, Marino F (1994) Social support and social structure: a descriptive epidemiology. J Health Soc Behav 35:513-519

30. Van Voorhees BW, Paunesku D, Kuwabara SA, Basu A, Gollan J, Hankin BL, Melkonian S, Reinecke M (2008) Protective and vulnerability factors predicting new-onset depressive episode in a representative of US adolescents. J Adolesc Health 42:605-616

31. Weist MD, Freedman AH, Paskewitz DA, Proescher EJ, Flaherty LT (1995) Urban youth under stress: empirical identification of protective factors. J Youth Adolesc 24:705-721 